\title{
The profile of professionals in health and education fields at work in their communities
}

\author{
Perfil de profissionais nas áreas de saúde \\ e educação atuando em suas comunidades
}

Mark Anthony Beinner 1

Rosana Passos Cambraia Beinner 1

1 Departamento de Enfermagem, Faculdade de Ciências da Saúde, Faculdades Federais Integradas de Diamantina/ FAFEID.

Rua da Glória 187, Centro, 39100-000, Diamantina MG. beinner@citell.com.br rosabeinner@fafeid.edu.br
Abstract Social roles mold attitudes of actors who play the part in the community, and affect behavioral and moral attitudes and social conscience. There is a diversity of behaviors that demonstrates the extension to which individuals are in constant participation in the community life. A group profile of professional's health and education may supply information on the disciplinary approach in Community Health. Objective: to examine the profile of professionals at work in the Health and Education fields. Subjects participated in answering questions concerning professional work, leisure/religious activities, feeding/sleep habits, prevention and contraceptive methods, medical and/or psychological treatment and medicine/herbal use. Characteristics of the professional group regarding life style and the paradox of the practice of safe sex behavior were recorded. There exists the possibility to improve the quality of life for people in communities by reducing the sources of stress and tension by promoting physical and mental health. Methods should be investigated to allow for the promotion of a quality of life in a small fraction of the population engaged in health and education work in their own communities.

Key words Community, Education, Quality of life, Public health
Resumo Papéis sociais moldam as atitudes dos atores que participam na comunidade e afetam as atitudes comportamentais, morais e a consciência social. Há uma diversidade de comportamentos que demonstra a extensão em que os indivíduos estão em constante participação na vida da comunidade. O perfil de um grupo de profissionais em saúde e educação poderia fornecer informação disciplinar sobre a saúde da comunidade. Objetivo: examinar o perfil de profissionais da saúde e da educação. Os sujeitos participaram respondendo questões sobre trabalho profissional, atividades de lazer e religiosas, hábitos de alimentação e sono, métodos de prevenção e de contracepção, tratamento médico elou psicológico e uso de medicamentos/plantas medicinais. Observaram-se características do grupo de profissionais relacionadas com o estilo de vida e também o paradoxo do comportamento quanto à prática de sexo seguro. Existem condições de vida para as pessoas melhorarem suas comunidades, reduzindo fontes de estresse e tensão e promovendo saúde física e mental. Métodos poderiam ser investigados para tornar possível a promoção da qualidade de vida de uma pequena fração da população engajada no trabalho em saúde e educação em suas próprias comunidades.

Palavras-chave Comunidade, Educação, Qualidade de vida, Saúde pública 


\section{Introduction}

Human thought is hardly ever impartial. We require observation and systematic experimentation for comparing our ideas with reality. There is a growing conscience of subjectivity in scientific interpretation, occult values in concepts and labels of Social Psychology, and the abyss between what is scientific description and what should be the ethical standards. Social psychology research varies from localization and by method, correlational or experimental, and psychologists have related personnel and social factors to human health.

Actions are determined by social roles, which mold attitudes of actors who play a part in our community. Actions also affect our moral attitudes, and our racial and political behaviors in turn help mold our social conscience. Among the universal human similarities, the registered trademark of our specie is the capacity to learn and adapt. Evolution proportioned man the possibility to live in a creative manner in a world undergoing constant change where he must adapt to environmental changes. Diversity of languages, customs and expressive behaviors suggest that much of our behavior is socially programmed (Myers, 2000). Behaviors, ideas and traditions, which help to define a group, are transmitted from one generation to another. The extraordinary diversity of attitudes and behaviors from one culture to another demonstrates the magnitude to which we are end products of cultural roles and norms.

In relation to patterns of realization, a very high level of demands generally hinders the achievement of objectives resulting in negative repercussions on self-esteem (Del Prette \& Del Prette, 1999). Establishing realistic objectives and adapting compatible realistic expectations with ones own abilities and the conditions imposed by the situation constitute an important social-cognitive ability for characterization of social competence of the individual. In fact, several lines of investigation have demonstrated the benefits of a sense of effectiveness and control of sentiments (Myers, 2000; Bailis et al., 2001). Individuals who believe in self-competence, who possess internal control, are better prepared and achieve more results then those who have acquired a pessimistically abandoned perspective on life.

If the objective of psychology is the study of cognitive processes, learning, affective systems and emotions of man, his interpersonal and group relations which he establishes, a psychological glimpse would be the founded vision into the theories which support human cognition, learning, emotions between other such processes that form human behavior (Arendt, 1997).

Community psychology has its origin in social and preventive psychiatry on one extreme, and dynamic and group psychotherapy on the other, practices which consider social origin and the study of objects. Man has become more and more conscience of the importance of his involvement in the decision process aimed at resolving vital problems, which may lead to the transformation of environmental conditions (Arendt, 1997).

The study by Porto \& Almeida (2002) is based on a critical revision on the evolution and the characteristics of the workers' health area. The environmental and sanitation problems are examples of complex issues, because they involve the physical and biological environment, production, social organization, economy and cultural interaction of humans and their ecosystem. The alternative of small interdisciplinary groups depends on a combination of several elements, uniting professionals around problems whose definitions converge on a shared process of construction.

The risk situation is a construction that describes the situation in which the risk behavior results, and to some extent can initiate or promote risk behavior. For example, a risk situation may include drug abuse, conjugal difficulties, an unfamiliar environment, lack of condoms, financial difficulties or solitude, which may add to an insecure sexual behavior with an unknown partner more likely (Ross \& Pinto, 2000). Even under circumstances where an individual has a high degree of autonomy regarding behaviors related to health, the situation can increase the variation in the explanation of risk behavior.

A greater part of research on risk behavior in health focuses on personality and the individual's attitudinal characteristic, with little attention on the situation in which the risk is located. With the task of quantifying the variation of risk behavior, the situation can supply a series of variances not foreseen previously (Ross \& Pinto, 2000). Understanding the sources of these additional variances can assist Public Health professionals to identify the situational variables that are potentially modified, and at the same time, call attention to the interactions between people and the situation. 
In the industrialized world, mortality is strongly linked to behavior - the consumption of cigarettes, alcohol, drugs, a poor diet, stress, lack of exercise and failure to follow medical advice (Myers, 2000). Work has been underway to study and change these contributions of behavior to disease, resulting in the creation of a new multidisciplinary field, which will study how people react to the symptoms of diseases and exactly which emotions and explanations influence health.

State Education and Health agencies tend to agree that the educator's acceptable performance in health depends on authorities concrete administrative support may provide them, in the form of a job description of their duties and responsibilities of the specialists' professional role in health and education (Candeias et al., 1991). An analysis of the results allows officials to outline a technical proposal, the objective being to increase the quality of education activities in public health programs.

In developing countries, risk situations and the reality of inadequate Public Health are themes of extensive studies. In a faraway Brazilian region located in the Northeastern Jequitinhonha Valley of the state of Minas Gerais, there is great need for qualified health and educational human resources. This same region unfortunately presents one of the lowest $\mathrm{Hu}$ man Development Indexes (HDI) in the country. To complicate the socioeconomic context of the Jequitinhonha Valley, the ever-increasing problem of drought has resulted in the inability of the Valley's population to be self-sustainable in food production. Like drought, malnutrition has for many years been responsible for foreseeable damages to health, combined with insufficient basic sanitation due to the lack of community services and social control in the region.

In one important reference city located in the upper region of the Jequitinhonha Valley, the city of Diamantina, are headquarters to several government administrative agencies responsible for the elaboration and implementation of Public Health and Education agenda. The population of Diamantina is approximately 44,259 (IBGE, 2000), however, considered a small city, it is an important reference center for the more than one million inhabitants who live along the upper, middle and lower Valley. Activities such as personnel training regularly held meetings and seminars beneficial for contributing new information and ideas are frequently sponsored by public, private and philanthropic organizations from the region. In Diamantina, there are two schools of higher education, which offer annually twelve undergraduate courses in health and education, which attracts an expressive number of students from surrounding towns and cities.

The profile of professionals from the Health and Education fields residing within the Jequitinhonha Valley was studied. We examined and evaluated their technical knowledge and how it may influence their quality of life. The question arises as to how psychosocial behavior of individuals affect the well being and quality of life of these professionals who reside within the same environment. As we are continually evaluating the psychosocial behavior of individuals from the community on a daily basis, we sometimes wonder about the health of those who work on the front lines in the Health and Education fields.

The objective of this study was to examine the profile of undergraduate professionals from Health and Education fields in a region of the Jequitinhonha Valley, Minas Gerais, Brazil. The group under investigation works in the communities where they live, disseminating information in health and behavior, and represent individuals striving towards professional qualification at the specialization level in Public Health Education.

\section{Methodology}

Participants: 35 undergraduate professionals (9 M; $26 \mathrm{~F}$, mean age $36 \mathrm{y}$ ).

Instrument: A 15-item questionnaire, which centered on professional work and typical daily habits, such as leisure/religious activities, feeding/resting habits, prevention and contraceptives use, frequency of sexual intercourse, if currently seeking medical/psychological treatment, self-medication use and medicine/herbal use, was applied to all participants.

Local: City of Diamantina, upper region of the Jequitinhonha River Valley, in the Northeast state of Minas Gerais, Brazil.

Conditions: The Federal Integrated Faculties of Diamantina (FAFEID), in conjunction with the Diamantinense Foundation (FUNDAEPE), offers a specialization course (latu sensu) entitled Public Health in Education, which is a multi-professional enrollment program offered to professionals who have concluded their undergraduate training. Partici- 
pants receive a generalized overview of concepts in Public Health, mental and affective disorders, besides psychological aspects of community health. Upon conclusion of the course, participants were given the opportunity to partake in a self-evaluation process.

Procedure: After consent from each participant was obtained, the questionnaire was handed-out to each person in the classroom. There was no time limit for answering the questions. The data was evaluated using a computer and EPINFO software, version 6.1 (1996).

\section{Results}

The table 1 presents a health profile of the respondents. The participants possessed multiprofessional, undergraduate backgrounds in Public Health: Dentists, Nurses, Physiotherapists, Nutritionists and Pharmacists, as well as those from the educational fields: Education, History and Law. The outstanding features from the questionnaire showed: 1) $72 \%$ partake in leisure activities; 2) $87.5 \%$ regularly attend religious services; 3) 49\% eat at least 4 meals /day; 4) 73\% of the 35 respondents slept between 6-8 hours/night and described their sleep patterns as good to satisfactory; 5) $54.5 \%$ engaged in sexual intercourse at least once a week;
6) $21 \%(23.1 \%$ females and $11.1 \%$ males $)$ indicated that they were seeking medical/psychological treatment; and 7) $82.4 \%$ responded to the question regarding knowledge of someone, whether a relative or friend from their community, who suffers from depression. An additional observation, which called attention to this study was that $78.2 \%$ of the participants considered themselves Catholic, however $56.7 \%$ of the respondents use condoms as a means for preventing sexual disease and/or unwanted pregnancies.

\section{Discussion}

The results presented by the health and education participants will contribute towards improving knowledge and add insight in Public Health regarding attitudes and the specific daily behaviors of those who work in Public Health and Educational fields, particularly professionals from this underdeveloped region. Participants from this study are employed by the $\mathrm{Mu}$ nicipal, State or Federal Health and Education agencies. All of the participants obtained their technical qualification from accredited universities, and with time, molded their professional performance as a result of working in their own communities.

\begin{tabular}{|c|c|}
\hline \multicolumn{2}{|c|}{$\begin{array}{l}\text { Table } 1 \\
\text { Selected responses from health and education professionals concerning typical daily habits. } \\
\text { The participants possess multiprofessional, undergraduate backgrounds in Public Health } \\
\text { and Educational fields. }\end{array}$} \\
\hline & Percent of the subjects (\%) \\
\hline \multicolumn{2}{|l|}{ Activities: } \\
\hline Leisure & 72.0 \\
\hline Religion (catholic) & $87.5(78.2)$ \\
\hline 6-8 hours sleep/day & 73.0 \\
\hline Eat at least 4 meals/day & 49.0 \\
\hline \multicolumn{2}{|l|}{ Sexual behavior: } \\
\hline Sexual intercourse/weekly & 54.5 \\
\hline Use of condoms & 56.7 \\
\hline Medical/psychological treatment & 20.6 \\
\hline \multicolumn{2}{|l|}{ Treatment duration: } \\
\hline About 2 years & 57.0 \\
\hline About 6-12 months & 28.6 \\
\hline Use medication & 20.6 \\
\hline Occasional headache & 50.0 \\
\hline Family members experiencing health problems & 50.0 \\
\hline Know someone experiencing depression & 82.4 \\
\hline Use herbal teas as a remedy & 47.1 \\
\hline
\end{tabular}


Quality of life is a term frequently cited from the most varied publications concerning evolution and therapy under diverse clinical conditions. It is usually difficult to evaluate quality of life because of its varied conceptions; from physical capacity to social performance; subjective ideas of well-being and the satisfactory insertion in a cultural context (Assumpção et al., 2000; Raphael et al., 2001). The observation of behaviors of Health professionals who should be conscious of their own behavioral changes, which could result in health problems if gone unchecked, proves supportive for understanding the roles of these professionals in the community who interact and who exercise influence with their own lifestyle.

Health and happiness are influenced not only by social cognition, but also by social relationships. Intimate relationships help people confront stress; above all, the relationship gives them the opportunity to share their most inner emotions with their partner. Life's existence is full of happiness and pain, both experiences are not excluded one from the other; on the contrary, they are complementary (Lillo, 1999). Both experiences make possible the emotional richness of life.

The style of life observed among the professionals in the present study reveals that the characteristics of their communities interfere in the quality of their life, associated strongly with their technical background gained from professional training and work experience. Their relationship with relatives and other individuals living in the same environment suggest the possibility of learning based on problem solving, which may be an interesting way to promote behavioral changes in Health and Education. Aspects of local culture, social values and environmental quality are related to the satisfactory inclusion of people in their communities and to the positive influence of their lifestyle.

Religious involvement is associated with decreased mortality, indicating that people with an active religious involvement are more likely to live longer and with greater harmony (McCullough et al., 2000; Hummer et al., 1999; Oman \& Reed, 1998; Kark et al., 1996). The association between religious involvement and mortality can be partly explained as a function of demographic and psychosocial variables related to health. Even today there are a large number of religiously active people, and there is an interesting favorable association with mortality, a healthy phenomenon that has some relevance to a substantial portion of the population (McCullough et al., 2000).

One example of religious faith and staying healthy is the paradox of behavioral attitudes towards the practice of safe sex. According to some religions, the Catholic Church in particular, the use of contraceptives and preservatives has always been vehemently condemned by the Vatican, and on the other hand, many religious leaders continue to avoid discussion of the importance of preventing transmission of sexual diseases, especially AIDS. In our study, 78.1\% of the participants responded as being Catholic and $56.7 \%$ regularly use condoms during sexual intercourse. This example clearly demonstrates the dissonance Health and Education professionals face in an era of an AIDS pandemic. Certainly one has to consider the predicament faced by most of these professionals who profess to be faithful religiously and who also worry about their own health's safety, and those in the community where preventive campaigns targeted at safe sex are a vital importance to society's well-being.

The principle cognitive components of social abilities are former knowledge (culture, environment, social roles), expectations and beliefs (plans and goals, values, means of accomplishment), strategies and methods for processing information. Although there exists general norms for interpersonal acting, similar in different cultural contexts, each social group ends up developing some particular type of norms. In this manner, a large part of the norms govern to an extent how people behave given their habits and group values. Deriving from a subculture of a small group consists the family, the context of work or neighborhood (Del Prette \& Del Prette, 1999). The undergraduate professionals who participated in this study obtained their skills and training from an accredited undergraduate university, satisfying the academic requirements of the institution, which qualified them as professionals. In addition to their technical qualifications, which provides incentives for specialized work, and the achievement of goals stipulated by curriculum requirements based on rules and regulations, the process of student evaluation contributed in part towards molding the undergraduate professional's conscious of his private life and his responsibilities in the community.

Although the regional environment where the undergraduate professional, who took part 
in this study, is considered less economically developed in relation to material resources, hygiene and sanitation, recommended daily nutritional caloric intake of foods and nutrients, lack of employment opportunities, which in turn propagates a vicious cycle of physical and mental family suffering, under such conditions, he must look for creative avenues given local perspectives. On one hand, the presence of community resources and agencies supported in large part by government, are seen as serving social support by minimizing the effects of stress and social exclusion, and mitigating in part some of the effects of low income and social status (Raphael et al., 2001). Leadership occasionally arises among professionals and is many times confused with the real objective of seeking political power as a means to an end.

Social inequality does not appear to appropriately describe social and economic realities. However, new realities require new language, which should accentuate action, malleability, flexibility, and the multitude of resources, and the heterogeneity of social structures. It is also worth mentioning here to what extent individuals and groups have the power to use and transform these structures once produced to significantly reduce the vulnerability to the forces of inequality (Stehr, 2000). A condition, which makes it possible for obtaining an ample basis of action with more frequency, is knowledge, that is to say, a combination of more general, accessible social aptitudes, whose impact on social structures of inequality accelerates the actor's opportunities to reformulate social constructions.

The citizenship dimension covers the social acting of individuals, involving society as a whole, as well as a continued acquisition of learning (Jacobi, 2002). The consolidation of participative proposals represents the potentialization and expansion of community practices, through the establishment of institutional mechanisms that exercise knowledge of effective rights and stimulate strategies of involvement and responsibility.

The fact that an individual is employed many times results in some improvement in the quality of life, mental health, and social inclusion. Work is both a health issue and a major determinant of social inclusion. Thus, while the therapeutic benefits of the work can be reaped, the onus is clearly on practitioners, services and communities to provide diverse work opportunities as a vehicle by which social inclusion can be achieved. Employment must become a fundamental part of every service user's health plan: work history, experience and aspirations must be assessed along with a careful assessment of actual and potential difficulties in order to develop a support package that meets each user's specific work and employment choices and needs (Evans \& Repper, 2000). While there exists evidence that work may be therapeutic, there are models for improving work environments, which can be applied to influence local and regional outcomes.

Health, education and housing sectors demand, besides political effort, social priorities whose returns will be foreseen during the long term. Unfortunately, in a world of globalized, capitalistic economies, where financial speculation is seen as a frenzy movement of greed, preferences are given to rapidly generated applications and the priority of wealthy returns. Within the globalized economic-financial panorama are situated the users of health and the providers of services of healthcare, given that medical-hygiene assistance to the population must constitute as an administrative priority (Cunha, 1999).

A great number of health services spend a considerable amount of energy and resources on development, implementation and maintenance of programs to promote continuous quality improvement. From a Public Health standpoint, quality improvement in health necessarily involves changing poor practice into good practice and good practice into excellent practice (Pearson, 2000). It is therefore necessary to explore the overall climate for innovation and creativity in the practice of Health and Education. To put these ideas into practice, however, requires that Health professionals maintain a continued acquisition of training, creativity and the power to innovate.

The support to undergraduate professionals located in distant, poor regions with peculiar characteristics such as described in the present study, should be more conscious of their community role, together with family members in a society where they work. The leadership of qualified and conscious members could be stimulated starting from the individual's attention regarding the future and well being of those that they are closer and dearer to. 


\section{Conclusion}

The adjustment process depends on the quality of life for people to improve their community: reduce sources of stress and tension by creating resources, which will promote physical and mental health. Thus by improving the socioeconomic picture beginning with the creation of employment and social well-being, will require the commitment of Health educators who should be alerted of the vital community role they play extending beyond their professional abilities.

New methods should be employed and tested with the aim of investigating forms such as how a small fraction of the population, trained and equipped in Health and Education, could proportion quantitatively better the quality of life of the population. Modern resources in communication and information access should be created in alliance with local, traditional, cultural resources such as prose, poetry, music and dance, making possible an interaction between knowledge and science together with religion and culture.

The incentive towards creativity and innovative ability, which many individuals desire can promote, on a local level, proposals for resolving stalemates, and those professionals with an integrated profile of their community environment, will be potential targets for successful multiplier programs.

\section{References}

Arendt RJJ 1997. Community psychology: theory and methodology. Psicologia, Reflexão e Crítica 10:1-5.

Assumpção FB, Kuczynski E, Sprovieri MH \& Spider EMG 2000. Scale of evaluation of life quality. Arquivos de Neuropsiquiatria 58:119-127.

Bailis DS, Segall A, Mahon MJ, Chipperfield JG \& Dunn EM 2001. Perceived control in relation to socioeconomic and behavioral resources for health. Social Science and Medicine 52:1661-1676.

Candeias NM, Abujamra AMD \& Pereira IMTB 1991. The delineation of the professional rolls of health education specialists - the technical proposal. Revista de Saúde Pública 25:289-298.

Cunha F 1999. Attendance to health: a critical revision. Brazilian Medical Association 45:1-3.

Del Prette ZAP \& Del Prette A 1999. Psicologia das habilidades sociais: terapia e educação. Vozes, Petrópolis.

Evans J \& Repper J 2000. Employment, social inclusion and mental health. Journal of Psychiatric Mental and Health Nursing 7:15-24.

Hummer RA, Rogers RG, Nam CB \& Ellison CG 1999. Religious involvement and US adult mortality. Demography 36:273-285.

IBGE 2000. Instituto Brasileiro de Geografia e Estatística. Estatcart, versão 1.1 - Sistema de Recuperação de Informações Georreferenciadas. CD-Rom.

Jacobi PR 2002. Local social policies and the challenges of citizens participation. Ciência \& Cultura 7(3):443454.

Kark JD et al. 1996. Does religious observance promote health? Mortality in secular vs. religious kibbutzim in Israel. American Journal of Public Health 86:341-346. Lillo SP 1999. O temor e a felicidade. Beca, São Paulo.
McCullough ME, Hoyt WT, Larson DB, Koening HG \& Thoresen C 2000. Religious involvement and mortality: the goal-analytic review. Health Psychology 19:211-222.

Myers DG 2000. Psicologia social. (6a ed.). LTC, Rio de Janeiro.

Oman D \& Reed D 1998. Religion and mortality among the community-dwelling elderly. American Journal of Public Health 88:1469-1475.

Pearson A 2000. Improving health care through innovative practice. International Journal of Nursing Practice 6:1.

Porto MFS \& Almeida GES 2002. Meanings and limits concerned to the strategies of disciplinary integration: a reflection about the contributions from the workers' health field. Ciência \& Saúde Coletiva 7(2): 335-347.

Raphael D et al. 2001. Making the links between community structure and individual well-being: community quality of life in Riverdale, Toronto, Canada. Health \& Place 7:179-196.

Ross MW \& Pinto JF 2000. Toward the public health of situations: the re-contextualization of risk. Cadernos de Saúde Pública 16:59-71.

Stehr N 2000. Class inequality to the knowledge inequality. Revista Brasileira de Ciências Sociais 15:101-112.

Artigo apresentado em 2/4/2003

Aprovado em 5/5/2003

Versão final apresentada em 15/10/2003 